\title{
Sex Differences in the Effects of Early Experience on the Development of Behavioral and Brain Asymmetries in Rats ${ }^{1}$
}

\author{
DIANNE M. CAMP, TERRY E. ROBINSON² AND JILL B. BECKER \\ Department of Psychology and Neuroscience Laboratory Building \\ The University of Michigan, Ann Arbor, MI 48104-1687
}

Received 29 August 1983

\begin{abstract}
CAMP, D. M., T. E. ROBINSON AND J. B. BECKER. Sex differences in the effects of early experience on the development of behavioral and brain asymmetries in rats. PHYSIOL BEHAV 33(3) 433-439, 1984.-The influence of early experience (preweaning handling) on the development of several postural/motor asymmetries (side bias in an open field, turn preference in a T-maze, amphetamine-induced rotational behavior, tail pinch-induced asymmetries) and the lateralization of brain dopamine was studied in adult male and female rats. In many cases the adult patterns of behavioral and brain asymmetries were modified by early handling in a sexually dimorphic manner. In addition, the direction of postural/motor asymmetries was very much task-dependent, especially in females. We conclude that: (1) early experience may modify the development of behavioral and brain asymmetries; (2) sex differences in asymmetries are very common; (3) early handling may affect males and females differently; and (4) different measures of postural/motor asymmetries may reflect different and multiple brain asymmetries.
\end{abstract}

Sex differences Asymmetries Early handling Striatum Dopamine Rotational behavior Nucleus accumbens Early experience Lateralization

FOR many years it was thought that humans were unique in having lateralized brains because reports of asymmetries in nonhuman animals were so rare. However, brain and behavioral asymmetries have now been described in several nonhuman species (e.g., rats, cats, birds and nonhuman primates; see $[9,29,31,32,40]$ for reviews). Although there is considerable evidence for brain and behavioral asymmetries in both humans and nonhumans there is also considerable variability in the pattern of these asymmetries [26,32]. Unfortunately, we know very little about the causes of this individual variation in any species. It has been previously suggested that one factor that may modify the development of cerebral asymmetries in both humans and rats is early experience $[9,23]$. To further explore this idea we investigated the effects of early handling on the development of several behavioral (postural/motor) asymmetries in rats. In addition, we examined the relationship between postural/motor asymmetries, and asymmetries in a neural system that has been implicated in some behavioral asymmetries-the nigrostriatal dopamine (DA) system $[18,39]$.

Sex differences have been reported in brain and behavioral asymmetries in both nonhumans $[31,32]$, and humans [27], as well as in the effects of early experience on behavior [43]. This suggests that males and females may differ in either the direction or strength of postural/motor asymmetries, and that early experience might influence the development of postural/motor asymmetries differently in males and females. To test these hypotheses we studied both male and female rats.

Lastly, we were interested in the relations between different measures of postural/motor asymmetries, i.e., can one generalize from results obtained with one measure of a postural/motor asymmetry to others? This is an important question because of the tendency to use one measure of a postural/motor asymmetry as an indicator of the direction of a unitary "brain asymmetry."

\section{METHOD}

\section{Subjects and Handling Procedure}

Newborn litters of Holtzman rats (Sprague-Dawley derived; Madison, WI) were sexed and culled to 10 pups per litter with equal, or nearly equal numbers of males and females. Whole litters $(n=8)$ were then randomly assigned to either a handled $(\mathrm{H})$ treatment group or to a nonhandled (NH) control group. Each day, from day 1 through day 21 , pups from the $\mathrm{H}$ group were removed from their mother and placed for 3 minutes into individual compartments containing sawdust (e.g., [8]). They were then returned to their

\footnotetext{
'This study was supported by PHS grant NS16437 to T.E.R. Dr. Becker was supported by NRSA award ND05997. ${ }^{2}$ Requests for reprints should be addressed to T. E. Robinson, Neuroscience Laboratory Building, The University of Michigan, 1103 E.
Huron St., Ann Arbor, MI 48104-1687.
} 
mother in the breeding cage. Animals in the four NH litters were not disturbed until they were weaned. On day 22 the pups from all litters were weaned, earpunched, weighed, and then housed in groups of 2 to 4 , with rats from the same litter together, and males and females separated. At 51 days of age all animals were placed into individual wire hanging cages. Except for weighing each week, animals were not disturbed until they were 79 days old, when testing began. The animal room was kept on a reverse light/dark cycle $(14: 10 \mathrm{hr})$, with the lights going off at 8:00 hr.

\section{Procedures for Measuring Postural/Motor Asymmetries}

Four different tests were used to assess postural/motor asymmetries. All testing occurred during the dark part of the rats ' light/dark cycle (between 10:00 and 14:00 hr). Except for AMPH-induced rotation, all testing was done under dim, red light

Side preference in an open field. Rats were individually placed within an L-shaped barrier in one of the corner squares of an open field apparatus. The open field was divided into 16 equal squares $\left(30 \mathrm{~cm}^{2}\right)$ by lines painted on the floor. After 10 seconds the barrier was removed (without regard to the rat's position), and a 3 minute observation period began. A record was made of whether the rat initially moved into the adjacent square along the left-hand wall or right-hand wall, into the inner square, or did not leave the starting position. Rats were given one trial per day for 4 successive days. The L-shaped barrier was placed in a different corner each day, the order randomly determined for each animal. Any preference for one direction or the other was determined by calculation of a directionality score: $D S=(R-L) /(\sqrt{R+L})$ - where $R$ equals the number of responses to the right and $L$ equals the number to the left (see [38]). The strength of asymmetry was also estimated from the DS, but without regard to the direction of preference.

Amphetamine-induced rotation. Rotational behavior was measured with the use of automated spherical rotometers as described previously [30]. After a 15 minute habituation period each rat was injected (IP) with d-amphetamine sulfate (AMPH) dissolved in $0.9 \%$ saline and rotational behavior was recorded for 1 hour. Male rats received $1.2 \mathrm{mg} / \mathrm{kg}$ of AMPH and females $0.85 \mathrm{mg} / \mathrm{kg}$. These systemic doses have been shown to produce equivalent brain levels of AMPH in male and female rats [3]. AMPH-induced rotation varies across the estrous cycle [3], and therefore all females were tested on the day of estrus as determined by vaginal smears and behavioral receptivity. Males were briefly handled on the days smears were taken to control for any effects of additional handling. Each animal was tested for AMPHinduced rotational behavior on two occasions, with 3 weeks separating the two test sessions. The number of net rotations (the number of $360^{\circ}$ turns in the dominant direction minus those in the other direction) was determined for each animal and used to estimate the strength of any asymmetry.

Tail pinch-induced asymmetries. Rats were placed into a $58 \mathrm{~cm}^{2}$ observation chamber that had wood shavings scattered on the floor. After a 5 min habituation period a large paper clip wrapped with adhesive tape was placed near the end of the rat's tail. The pressure was adjusted so as not to cause obvious extreme distress, but tight enough so the rat would orient to it. The total amount of time the rat spent deviated to the right or to the left during a 5 minute observation period was recorded. A rat was considered to be in a lateralized position if there was any detectable lateral deviation from an imaginary straight line drawn down the spine. The percent of the total test interval that an animal spent deviated to the right or left was used as an estimate of the strength of the asymmetry.

Side preference in a $T$ mare. Rats were individually placed into the start end of a Plexiglas $T$ maze (alle $y=45 \mathrm{~cm}$ long; each arm $=30 \mathrm{~cm}$ long). After 2 to $3 \mathrm{sec}$ electrical current $(0.6 \mathrm{~mA})$ was passed through the grid floor until the rat escaped by entering one of the side arms (left or right) of the maze. Each test consisted of 10 trials with $151030 \mathrm{sec}$ between trials. The animals were tested on three separate occasions. with the first two tests separated by 2 days, and the third given approximately one month later. The strength of any side preference was estimated by calculating the percent of the total trials in which the preferred arm was entered. without regard for direction.

\section{Neurochemical Analysis}

Approximately one month after the last behavioral test, when the animals were about 150 days of age, they were decapitated, and the right and left striatum and right and left nucleus accumbens rapidly dissected from the brain. The tissue was weighed and then homogenized in $0.05 \mathrm{~N} \mathrm{HClO}_{4}$. Tissue concentrations of dopamine were determined by high performance liquid chromatography with electrochemical detection using procedures adapted from Felice $e t$ al. [15].

\section{Statistical Analyses}

Data on postural/motor asymmetries were analyzed in two different ways: (1) the presence and direction of leftright asymmetries were analyzed using chi square tests; and (2) differences in the degree (or strength) of asymmetries were assessed using two-way analyses of variance with one nested factor and unequal n's. Preliminary tests for litter effects showed no significant effects for any of the measures $(p>0.25)$, and therefore this error was pooled with the residual error [44]. T-tests were used for individual comparisons. In addition, the data were subjected to correlational analyses and multiple regression.

\section{RESULTS}

\section{Side Preference in an Open Field}

Handled male rats, but not NH males, had a significant leftward bias in the open field $\left(\chi^{2}=3.8, p<0.05\right.$; see Table 1$)$. In contrast, $\mathrm{NH}$ but not $\mathrm{H}$ females had a leftward bias $\left(\chi^{2}=4.6, p<0.03\right.$; Table 1$)$. These results confirm earlier reports by Sherman et al. $[37,38]$. In fact, the directionality scores we obtained for $\mathrm{H}$ males $(-0.3768$; differs from zero, $t=1.64, p<0.061)$ and $\mathrm{NH}$ females $(-0.510$; differs from zero, $t=2.35, p<0.016$ ) were remarkably similar to those reported by Sherman et al. ([37,38]; -0.3862 and -0.508 respectively). There was no difference in the strength of the asymmetry in the open field (i.e., how consistently an individual turned in the same direction) between $\mathrm{H}$ and $\mathrm{NH}$ animals $(\mathrm{F}=2.14, p<0.15)$ or between males and females $(\mathrm{F}=1.89)$

\section{AMPH-Induced Rotation}

In contrast to the findings in the open field, there was no left/right bias in the direction of rotational behavior in $\mathrm{H}$ animals. Only NH males showed a consistent population 


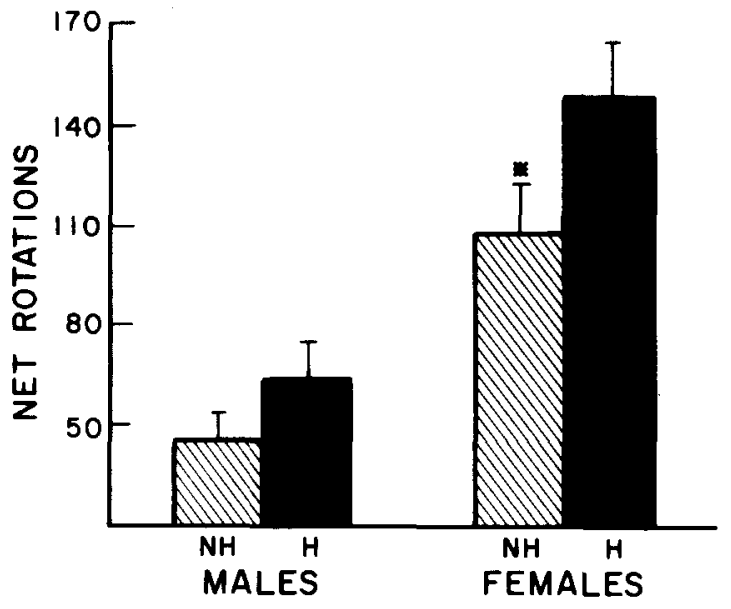

FIG. 1. The mean ( \pm S.E.M.) number of net rotations made by handled $(\mathrm{H})$ and nonhandled (NH) male and female rats during the 60 min after amphetamine administration. Females differed from males $(p<0.001)$ and $\mathrm{NH}$ females from $\mathrm{H}$ females $(p<0.03)$.

bias, turning preferentially to the left, i.e., counterclockwise $\left(\chi^{2}=4.0, p<0.05\right.$; see Table 1). Both handling and sex influenced the vigor of rotational behavior, as indicated by the number of net rotations. Females made significantly more net rotations than males $(\mathrm{F}=28.0, p<0.001$, Fig. 1$)$, and $\mathrm{H}$ animals made more than $\mathrm{NH}$ animals $(\mathrm{F}=4.93, p<0.03$, Fig. 1). Although there was not a significant interaction, individual comparisons indicated that the main effect of handling was largely accounted for by the difference between $\mathrm{H}$ and $\mathrm{NH}$ females $(t=2.1, p<0.04$; Fig. 1). The $\mathrm{H}$ females made more net rotations than NH females not only because they made more full rotations in the dominant direction, but fewer rotations in the non-dominant direction. Therefore, to the extent that the number of net rotations provides an index of how strongly lateralized animals are in a test of rotational behavior, females were more lateralized than males, and $\mathrm{H}$ females more lateralized than NH females.

\section{Tail Pinch-Induced Asymmetry}

Again, the only left-right asymmetry observed with this measure occurred in NH animals, and only in NH females $\left(\chi^{2}=12.8, p<0.001\right.$; Table 1$)$. Ninety percent of the NH females showed a rightward bias when tail pinched. No left-right asymmetries were evident in $\mathrm{H}$ males or females, or $\mathrm{NH}$ males. We also found differences in the strength of tail pinch-induced asymmetries. Handled males and females and NH males spent a comparable percent of the total 5 min test session in a lateralized posture $(25.9 \pm 2.5,30.0 \pm 3.4$, and $27.3 \pm 3.2$ percent, respectively). In contrast. $\mathrm{NH}$ females spent $46.8 \pm 2.8$ percent of the test session in a lateralized posture. An analysis of variance resulted in a significant sex $\times$ handling interaction $(F=7.2, p<0.01)$, and subsequent pairwise comparisons (Newman-Keuls) revealed that $\mathrm{NH}$ females spent more time in a lateralized posture than any of the other 3 groups, which did not differ from each other.

\section{Side Preference in a T-Maze}

In the T-maze both $\mathrm{NH}$ males and females showed a similar leftward bias $\left(\chi^{2}=4.3\right.$, and 5.6, $p<0.04$ and $p<0.02$ respectively; Table 1). The $\mathrm{H}$ females tended to have a left bias, but it did not reach statistical significance $\left(\chi^{2}=2.6\right.$, $p<0.12$ ). On the other hand, there was no hint of left-right asymmetry in $\mathrm{H}$ male rats. All animals showed a strong side preference on this task, entering the same arm on $90 \%$ of the 30 trials. Therefore, it is not surprising that we did not find any differences between groups in the strength of this asymmetry.

Asymmetries and Sex Differences in Striatal and Nucleus Accumbens DA Concentrations

Table 2 shows the levels of DA in the left and right striatum and nucleus accumbens for all groups. We report for the first time a left-right asymmetry in the DA content of the nucleus accumbens in $\mathrm{H}$ male rats $(\mathrm{R}>\mathrm{L} ; t=2.17$, $p<0.044$; Table 2 ). This asymmetry is probably not unique to males because $\mathrm{H}$ females also showed a strong tendency for higher right than left nucleus accumbens DA levels, although the difference did not quite reach statistical significance $(t=1.79, p<0.09$; Table 2). Non-handled rats of neither sex had this asymmetry in nucleus accumbens, and no left-right asymmetry was found in the striatal DA levels for any of the groups.

To estimate the magnitude of any neurochemical asymmetry, without regard for direction, the DA concentration on the side with more DA was expressed as a ratio of the side with lower DA (Table 2). Analyses of variance revealed no effect of handling or sex on the magnitude of these absolute neurochemical asymmetries in either the striatum or nucleus accumbens. However, the difference in DA content between the right and left nucleus accumbens was significantly greater than the difference between the two striata, i.e., the high/low ratios for accumbens are greater than for striatum $(t=2.29, p<0.025)$.

Lastly, there is a sex difference in the total DA content (left plus right) of the nucleus accumbens, with males having higher concentrations of $\mathrm{DA}$ than females $(\mathrm{F}=4.03, p<0.048$; Table 2).

\section{Relations Between Neurochemical and Behavioral Asymmetries}

The relations between the 4 postural/motor asymmetries and possible asymmetries in the DA content of the striatum and nucleus accumbens were also examined. The DA content in the striatum and nucleus accumbens located ipsilateral vs. contralateral to each postural/motor side preference was compared using chi square tests and paired $t$-tests. Of the 32 chi square tests only 2 revealed a significant relationship between a postural/motor asymmetry and DA content. More NH male rats had higher DA levels in the striatum ipsilateral to their side preference when tail pinched, and more NH male rats had higher DA levels in the nucleus accumbens ipsilateral to their side preference in the open field. However, paired $t$-tests on the actual DA levels were not significant. Therefore, these data indicate no consistent relationship between the postural/motor asymmetries studied and asymmetries in the DA concentrations of the striatum or nucleus accumbens.

The last question addressed concerned whether the direction of one postural/motor asymmetry predicted the direction of a second postural/motor asymmetry. Table 3 shows the percent of animals that had the same side preference on the 6 possible pairs of postural/motor tests. Chisquare tests revealed no statistical relationship for any of the pairs of behavioral tests; i.e., the direction of one 
TABLE I

THE PERCENT $\%$ AND NUMBER (N) OF MALE AND FEMALE RATS IHAT WERE HANDLED (H) OR NOT HANDLED (NH, LAKI, Y IN I.I. THAT SHOWED A LEFT OR RIGHT SIDE BIAS, OR NO CONSISTENT LATERAL. PREFERENCE (NO PREFI. ON FOUR DIFIIRFNT IIISIS OI POSTURAL/MOTOR ASYMMETRY (SEE TEXT)

\begin{tabular}{|c|c|c|c|c|c|c|c|c|c|c|c|c|c|}
\hline \multirow[b]{3}{*}{ Test } & \multirow[b]{3}{*}{ TRT } & \multicolumn{6}{|c|}{ Males } & \multicolumn{6}{|c|}{ lemalus } \\
\hline & & \multicolumn{2}{|c|}{ Leti } & \multicolumn{2}{|c|}{ Right } & \multicolumn{2}{|c|}{ No Pref } & \multicolumn{2}{|c|}{ Lefi } & \multicolumn{2}{|c|}{ Right } & \multicolumn{2}{|c|}{ Nu Pref } \\
\hline & & Y/ & $N$ & y & $N$ & y & $N$ & $\%$ & $N$ & $\%$ & $N$ & $\because$ & $N$ \\
\hline \multirow[t]{2}{*}{ Side Pref-Open Field } & $\mathrm{NH}$ & 40 & 181 & 45 & (9) & 15 & (3) & 55 & $(11)^{*}$ & 15 & $(3)$ & 30 & (6) \\
\hline & $\mathrm{H}$ & 55 & $(10)^{*}$ & 16 & (3) & 31 & (6) & 40 & (8) & 30 & $16)$ & 30 & $(6)$ \\
\hline Turn Pref-Amphetamine & $\mathrm{NH}$ & 60 & $(12)^{*}$ & 20 & (4) & 20 & (4) & 40 & (8) & 50 & $(10)$ & 10 & 121 \\
\hline Induced Rotation & $\mathrm{H}$ & 47 & (9) & 42 & $(8)$ & 11 & (2) & 47 & (9) & 47 & (9) & 5 & $11)$ \\
\hline \multirow[t]{2}{*}{ Side Pref-Tail Pinch } & NH & 50 & $(10)$ & 50 & $(10)$ & & & 10 & (2) & 90 & $(18)^{*}$ & & \\
\hline & $\mathrm{H}$ & 58 & $(11)$ & 42 & $(8)$ & & & +58 & $(11)$ & 42 & (8) & & \\
\hline \multirow[t]{2}{*}{ Turn Pref-T Maze } & $\mathrm{NH}$ & 70 & $(14)^{*}$ & 25 & $(5)$ & 5 & (1) & 70 & $(14)^{: 5}$ & 20 & (4) & 10 & (2) \\
\hline & $H$ & 47 & (9) & 47 & (9) & 5 & (1) & 68 & (13) & 22 & (6) & 0 & (0) \\
\hline
\end{tabular}

* Left differs from right, $p<0.05$.

† Handled $(\mathrm{H})$ differs from nonhandled $(\mathrm{NH}), p<0.001$.

TABLE 2

THE MEAN ( + S.E.M) LEVELS OF DOPAMINE (DA) IN THE LEFT AND RIGHT STRIATUM AND NUCLEUS ACCUMBENS OF MALE AND FEMALE RATS THAT WERE HANDLED OR NOT HANDLED EARLY IN LIFE

\begin{tabular}{|c|c|c|c|c|c|}
\hline $\begin{array}{l}\text { Treatment } \\
\text { Group }\end{array}$ & Left & \multicolumn{2}{|r|}{ Right } & $(N)$ & \multirow[t]{2}{*}{$\begin{array}{c}\text { Ratio } \\
\text { High/Low }\end{array}$} \\
\hline \multicolumn{5}{|c|}{ Striatal DA (NG DA/MG Tissue) (Mean \pm S.E.) } & \\
\hline \multicolumn{6}{|l|}{ Males } \\
\hline Nonhandled & $13.49 \pm 0.51$ & 8 & $13.64 \pm 0.51$ & 12 & $1.07 \pm 0.01$ \\
\hline Handled & $13.73 \pm 0.58$ & 10 & $13.71 \pm 0.53$ & 8 & $1.07 \pm 0.01$ \\
\hline \multicolumn{6}{|l|}{ Females } \\
\hline Nonhandled & $12.65 \pm 0.39$ & 8 & $12.95 \pm 0.41$ & 11 & $1.08 \pm 0.01$ \\
\hline Handled & $13.83 \pm 0.63$ & 11 & $13.16 \pm 0.44$ & 7 & $1.10 \pm 0.03$ \\
\hline \multicolumn{6}{|c|}{ Nucleus Accumbens DA (NG DA/MG Tissue) } \\
\hline \multicolumn{6}{|l|}{ Males } \\
\hline Nonhandled & $8.12 \pm 0.44$ & 7 & $8.41 \pm 0.44$ & 12 & $1.12 \pm 0.03$ \\
\hline Handled & $8.82 \pm 0.55$ & 5 & $9.23 \pm 0.52^{*}$ & $14 \dagger$ & $1.10 \pm 0.02$ \\
\hline \multicolumn{6}{|l|}{ Females } \\
\hline Nonhandled & $7.96 \pm 0.52$ & 10 & $7.98 \pm 0.42$ & 8 & $1.14 \pm 0.03$ \\
\hline Handled & $7.59 \pm 0.39$ & 6 & $7.94 \pm 0.32 末$ & 13 & $1.11 \pm 0.02$ \\
\hline
\end{tabular}

*Left differs from right $(\mathrm{t}=2.17 ; p<0.044$; paired $t$-test, two-tailed $)$.

tLeft differs from right $\left(\chi^{2}=4.26 ; p<0.04\right)$.

$\$$ Left differs from right $(\mathrm{t}=1.79 ; p<0.09$; paired $t$-test, two-tailed $)$.

$\downarrow$ Nucleus accumbens differs from striatum $(\mathrm{t}=2.29 ; p<0.025$; two-tailed).

Males differ from females $(\mathrm{F}=4.03 ; 1.72 ; p<0.048)$. 
TABLE 3

THE PERCENT OF HANDLED (H) AND NONHANDLED (NH) MALE AND FEMALE RATS THAT SHOWED LATERAL PREFERENCES IN THE SAME DIRECTION IN TWO DIFFERENT TESTS OF POSTURAL/MOTOR ASYMMETRY

\begin{tabular}{lcccc}
\hline & \multicolumn{2}{c}{ Males } & \multicolumn{2}{c}{ Females } \\
$\begin{array}{l}\text { Behavioral Test } \\
\text { Pairs }\end{array}$ & NH & H & NH & H \\
\hline $\begin{array}{l}\text { AMPH-Induced Rotation } \\
\quad \text { T Maze }\end{array}$ & 56 & 50 & 47 & 56 \\
$\begin{array}{l}\text { AMPH-Induced Rotation } \\
\quad \text { Tail Pinch }\end{array}$ & 44 & 65 & 56 & 39 \\
$\begin{array}{l}\text { AMPH-Induced Rotation } \\
\quad \text { Open Field }\end{array}$ & 33 & 67 & 25 & 50 \\
$\begin{array}{l}\text { T Maze } \\
\quad \text { Tail Pinch }\end{array}$ & 42 & 50 & 33 & 37 \\
$\begin{array}{l}\text { T Maze } \\
\quad \text { Open Field }\end{array}$ & 65 & 58 & 58 & 43 \\
$\begin{array}{l}\text { Tail Pinch } \\
\text { Open Field }\end{array}$ & 70 & 62 & 28 & 46 \\
\end{tabular}

All possible pairs of tests are illustrated (see text).

postural/motor asymmetry did not predict the direction of a second postural/motor asymmetry. This was confirmed by multiple regression and correlational analyses.

\section{DISCUSSION}

The experiments reported here address 5 major questions concerning behavioral and brain asymmetries in rats. These are: (1) Does early experience (early handling) influence the adult pattern of behavioral and brain asymmetries?; (2) Are there sex differences in the adult pattern of behavioral and brain asymmetries?; (3) Are the effects of early experience on asymmetries different in males and females?; (4) Are postural/motor asymmetries related to asymmetries in the concentration of striatal or nucleus accumbens DA?; and (5) What are the relations between different measures of postural/motor asymmetries? Each of these issues will be discussed in turn.

Does Early Experience Influence Behavioral and Brain Asymmetries?

In a series of papers Denenberg and his colleagues have reported that early experience (handling) influences the subsequent effects of lateralized neocortical lesions in adults on open field behavior [10], right-left spatial bias in an open field [38], taste aversion learning [11], and muricide [16]. On the basis of these findings Denenberg ([9], p. 1) has hypothesized that early experience can, "induce laterality in a symmetric brain or facilitate its development in an already biased brain." The experiments reported here support the claim that early handling can influence the development of behavioral and brain asymmetries, but do not support the idea that the direction of the effect is always to enhance laterality.

The observation that $\mathrm{H}$, but not $\mathrm{NH}$ rats, had a significant $L / R$ asymmetry $(R>L)$ in nucleus accumbens $D A$ levels provides direct evidence of an effect of early experience on the lateral organization of the brain. In addition, we found that early handling in male rats resulted in a left-bias in the open field that was not evident in $\mathrm{NH}$ rats, as reported earlier by Sherman et al. [38]. However, in other tests of postural/motor asymmetries (rotation, tail pinch, T-maze) only $\mathrm{NH}$ animals showed population asymmetries; not $\mathrm{H}$ animals. Therefore, we must conclude that although early handling may enhance some types of brain and postural/motor asymmetries it may actually diminish others.

Are There Sex Differences in Behavioral and Brain Asymmetries?

The evidence reported here leaves little doubt that there are sex differences in behavioral and brain asymmetries. In fact, sex differences are more common than not [31,32]. In some cases the sex difference is in the direction of a side bias. For example, NH males had a left bias for AMPHinduced rotational behavior. Although the trend towards a right bias in females was not significant, Glick and Ross [20] found a significant right bias in females after testing hundreds of rats. In other cases females showed an asymmetry and males did not (e.g., tail pinch, side preference in the open field for nonhandled rats). Lastly, when the strength or magnitude of postural/motor asymmetries was estimated females were usually more strongly lateralized than males (e.g., rotational behavior, tail pinch).

Sex differences have previously been reported for other behavioral asymmetries in nonhuman animals, including handedness in mice [7], the vigor of rotational behavior in rats $[3,4,33]$, and neonatal rat tail posture [12,34]. In addition, sex differences in neurochemical and neuroanatomical asymmetries, and in the effects of lateralized lesions have been found (for reviews see $[31,32]$ ). Even if some of the examples of sex differences and asymmetries are spurious (and some probably are), the consistency with which sex differences have been reported across many different measures of behavioral and brain asymmetries suggests that sex is an extremely important variable in determining the pattern of cerebral asymmetry [31,32]. Thus, the brains of males and females may be organized more differently than traditionally thought.

Are There Sex Differences in the Effects of Early Experience on the Development of Asymmetries?

The idea that early experience may differentially affect males and females has previously been suggested on the basis of studies of exploration, shock-induced fighting, avoidance learning and adrenocortical reactivity $[14,42,43]$. The findings reported here support this claim, and further suggest that early experiences may have different effects on the development of asymmetries in males and females. In the open field early handling produced a leftward spatial bias in males that was not present in $\mathrm{NH}$ males. In contrast, $\mathrm{NH}$ females had a leftward bias that was not present in females that were handled prior to weaning. This pattern of sex differences in the effects of early handling is identical to that reported independently by Sherman et al. [37,38], and therefore would seem to be a robust effect. Also, $\mathrm{H}$ and $\mathrm{NH}$ females differed in their side bias when tail pinched, whereas there was no difference between $\mathrm{H}$ and $\mathrm{NH}$ males. It is possible that some of these sexually dimorphic changes in lateralization produced by early experience are causally related to other sex differences in behavior produced by early handling (e.g., $[14,43])$. 
Relations Between Postural/Motor Asymmetries and Striatal DA

Postural/motor asymmetries, such as handedness and rotational behavior, are usually thought to be due to an asymmetry in functional brain activity. This is a reasonable assumption if the postural/motor asymmetry is shown not to be due to an asymmetry in a peripheral structure, or a bias in the testing environment. The differences between $\mathrm{H}$ and $\mathrm{NH}$ males and females reported here make it unlikely that the postural/motor asymmetries found are due to such extraneous factors. It would be difficult to explain why $\mathrm{H}$ but not NH males showed a leftward bias in the open field, or why $\mathrm{NH}$ but not $\mathrm{H}$ males and females showed a leftward bias in the T-maze, by evoking a persistent environmental bias; especially since all rats were tested in the same apparatus, in a random order, by an experimenter blind to the treatment condition. Therefore, we presume that one or more neural asymmetries underlie these postural/motor asymmetries.

Very little is known about the neural basis of most behavioral asymmetries. The neural system that has been most extensively studied in relation to postural/motor asymmetries is the nigrostriatal system $[18,39]$. The evidence for an endogenous asymmetry in the nigrostriatal DA system is very strong $[17,18,19,21,22,33,45]$. For example, the differences between partial "dominant" vs. "nondominant"-sided 6-hydroxydopamine lesions of the substantia nigra are particularly striking [30]. Therefore, the lack of a relation between DA levels and postural/motor asymmetries reported here probably does not mean there is no relation between functional DA activity and behavioral asymmetries; but that resting neurotransmitter levels may be a poor indicator of functional brain activity. It is possible that with more sensitive indices of striatal activity relations between the kinds of postural/motor asymmetries reported here and striatal dopaminergic activity would emerge. This suggestion is supported by our observation in the present study that there was a small but significant negative correlation between the preferred direction of rotational behavior and caudate DA concentrations, i.e., left rotators tended to have higher right caudate $D A$ and vice versa $(r=-0.25$, $p<0.015$ ). It is also possible that some of the postural/motor asymmetries are related to other, and as yet unknown, neural asymmetries. For example, there was a weak but significant positive correlation between the preferred direction of tail pinch-induced postural asymmetry and caudate DA concentrations, i.e., caudate DA concentrations tended to be higher on the same side as the postural bias $(\mathrm{r}-+0.27$ $p<0.009$ ). Obviously, more research will be required to relate the growing list of neurochemical and neuroanatomical asymmetries in nonhumans [32] to behavioral asymmetries.

\section{Relations Between Different Postural/Motor Asvmenctrics}

Most rats showed a consistent lateral preference when repeatedly tested on the same measure of postural/motor asymmetry. However, there was no bias for one direction across different tests of postural/motor asymmetries (also see [28]). A comparison of the 6 different pairs of postural/motor asymmetries reported here resulted in no statistically significant relationship between any of the tests; i.e., the direction of one postural/motor asymmetry did not predict the direction of another. This lack of a consistent population asymmetry across different measures of lateral preference is very similar to that found in research on handedness in nonhuman primates. Monkeys consistently use the same hand to perform a specific unimanual task, but when faced with a different unimanual task are nearly as likely to use the other hand $[24,41]$. Therefore. whether the different behavioral asymmetries reported here are due to multiple and different neural asymmetries, or to some other cause is not clear. It is clear that no one behavioral test provides a sole index to a unitary "cerebral asymmetry." This should not be surprising because even in humans dichotic listening tasks, tachistoscopic tasks and handedness are not very reliable indicators of brain lateralization in individual subjects [5].

The mechanism(s) by which early handling influences brain and endocrine development to affect subsequent behavior has been the subject of considerable research, speculation and controversy $[1,13,25,35]$. Early handling affects adrenocortical maturation and function $[1,13,35]$, brain morphology $[2,36]$, and the phosphorylation of specific brain proteins [6]. Any of these factors could influence the development of brain and behavioral asymmetries. However, elucidation of what factors in fact do produce the kinds of effects reported here awaits further experimentation.

\section{ACKNOWLEDGEMENTS}

We thank Guy Mittleman and J. Keith Smith for assistance with the statistical analyses, Guy Mittleman for comments on an earlier version, and Marilyn Hoy for typing the manuscript. A preliminary version appeared in the Soc Neurosci Abstr, 8, 895, 1982.

\section{REFERENCES}

I. Ader, R. Early experience and hormones: emotional behavior and adrenocortical function. In: Hormonal Correlates of Behavior, vol 1, edited by B. E. Eleftheriou and R. L. Sprott. New York: Plenum Press, 1975, pp. 7-33.

2. Altman, J., G. D. Das and W. J. Anderson. Effects of infantile handling on morphological development of the rat brain: an exploratory study. Dev Psychobiol 1: 10-20, 1968.

3. Becker, J. B., T. E. Robinson and K. Lorenz. Sex differences and estrous cycle variations in amphetamine-elicited rotational behavior. Eur J Pharmacol 80: 65-72, 1982.

4. Brass, C. A. and S. D. Glick. Sex differences in drug-induced rotation in two strains of rats. Brain Res 223: 229-234, 1981.

5. Bryden, M. P. Laterality. Functional Asymmetry in the Intact Brain. New York: Academic Press, 1983.
6. Cain, S. and A. Routtenberg. Neonatal handling selectively alters the phosphorylation of a $47,000 \mathrm{~mol}$. wt. protein in male rat hippocampus. Brain Res 267: 192-195, 1983.

7. Collins, R. L. Toward an admissible genetic model for the inheritance of the degree and direction of asymmetry. In: Lateralization in the Nervous System, edited by S. Harnad et al. New York: Academic Press, 1977, pp. 137-150.

8. Denenberg, V. H. The effects of early experience. In: The Behaviour of Domestic Animals, edited by E. S. E. Hafez. London: Bailliere, Tindall and Cassell, 1969, pp. 96-130.

9. Denenberg, V. H. Hemispheric laterality in animals and the effects of early experience. Behav Brain $S_{c i}$ 4: 1-49, 1981.

10. Denenberg, V. H., J. Garbanati, G. Sherman, D. A. Yutzey and R. Kaplin. Infantile stimulation induces brain lateralization in rats. Science 201: 1150-1152, 1978. 
11. Denenberg, V. H., M. Hofmann, J. A. Garbanati, G. F. Sherman, G. D. Rosen and D. A. Yutzey. Handling in infancy, taste aversion, and brain laterality in rats. Brain Res 200: 123-133, 1980.

12. Denenberg, V. H., G. D. Rosen, M. Hofmann, J. Gall, J. Stockler and D. A. Yutzey. Neonatal postural asymmetry and sex differences in the rat. Dev Brain Res 2: 417-419, 1982.

13. Denenberg, V. H. and M. X. Zarrow. Effects of handling in infancy upon adult behavior and adrenocortical activity: suggestions for a neuroendocrine mechanism. In: Early Childhood The Development of Self Regulatory Mechanisms, edited by D. N. Walcher and D. L. Peters. New York: Academic Press, 1971, pp. 39-71.

14. Erskine, M. S., J. M. Stern and S. Levine. Effects of prepubertal handling on shock-induced fighting and ACTH in male and female rats. Physiol Behav 14: 413-420, 1975.

15. Felice, L. J., J. D. Felice and P. T. Kissinger. Determination of catecholamines in rat brain parts by reverse-phase ion-pair liquid chromatography. $J$ Neurochem 31: 1461-1465, 1978.

16. Garbanati, J. A., G. F. Sherman, G. D. Rosen, M. Hofmann, D A. Yutzey and V. H. Denenberg. Handling in infancy, brain laterality, and muricide in rats. Behav Brain Res 7: 351-359, 1983

17. Glick, S. D., T. P. Jerussi, D. H. Waters and J. P. Green. Amphetamine-induced changes in striatal dopamine and acetylcholine levels and relationship to rotation (circling behavior) in rats. Biochem Pharmacol 23: 3223-3225, 1974.

18. Glick, S. D., T. P. Jerussi and B. Zimmerberg. Behavioral and neuropharmacological correlates of nigrostriatal asymmetry in rats. In: Lateralization in the Nervous System, edited by S. Harnad et al. New York: Academic Press, 1977, pp. 213-249.

19. Glick, S. D., R. C. Meibach, R. D. Cox and S. Maayani. Multiple and interrelated functional asymmetries in rat brain. Life $S \mathrm{C} i$ 25: 395-400, 1979

20. Glick, S. D. and D. A. Ross. Right-sided population bias and lateralization of activity in normal rats. Brain Res 205: 222-225, 1981.

21. Jerussi, T. P. and S. D. Glick. Drug-induced rotation in rats without lesions: behavioral and neurochemical indices of a nor$\mathrm{mal}$ asymmetry in nigro-striatal function. Psychopharmacologia 47: 249-260, 1976.

22. Jerussi, T. P., S. D. Glick and C. L. Johnson. Reciprocity of pre- and postsynaptic mechanisms involved in rotation as revealed by dopamine metabolism and adenylate cyclase stimulation. Brain Res 129: 385-388, 1977.

23. Krashen, S. Lateralization, language learning and the critical period: some new evidence. Lang Learn 23: 63-74, 1973.

24. Lehman, R. A. W. The handedness of rhesus monkeys III. Consistency within and across activities. Cortex 16: 197-204, 1980

25. Levine, S. The pituitary-adrenal system and the developing brain. In: Progress in Brain Research, vol 32: Pituitary, Adrenal and the Brain, edited by D. deWied and J. A. W. M. Weignen. Amsterdam: Elsevier, 1970, pp. 79-85.

26. Levy, J. and R. C. Gur. Individual differences in psychoneurological organization. In: Neuropsychology of Left-Handedness, edited by J. Herron. New York: Academic Press, 1980, pp. 199-231.
27. McGlone, J. Sex differences in human brain asymmetry: a critical survey. Behav Brain Sci 3: 215-263, 1980.

28. Myslobodsky, M. S. and H. Braun. Postural asymmetry and directionality of rotation in rats. Pharmacol Biochem Behav 13: 743-745, 1980.

29. Nottebohm, F. Origins and mechanisms in the establishment of cerebral dominance. In: Handbook of Behavioral Neurobiology, edited by M. S. Gazzaniga. New York: Plenum Press, 1974, pp. 295-344.

30. Robinson, T. E. and J. B. Becker. The rotational behavior model: asymmetry in the effects of unilateral 6-OHDA lesions of the substantia nigra in rats. Brain Res 264: 127-131, 1983.

31. Robinson, T. E., J. B. Becker and D. M. Camp. Sex differences in behavioral and brain asymmetries. In: Hemisyndromes: Psychobiology, Neurology, Psychiatry, edited by M. S. Myslobodsky. New York: Academic Press, 1983, pp. 91-128.

32. Robinson, T. E., J. B. Becker, D. M. Camp and A. Mansour. Variation in the pattern of behavioral and brain asymmetries due to sex differences. In: Cerebral Lateralization in SubHuman Species, edited by S. D. Glick. New York: Academic Press, 1984, in press.

33. Robinson, T. E., J. B. Becker and V. D. Ramirez. Sex differences in amphetamine-elicited rotational behavior and the lateralization of striatal dopamine in rats. Brain Res Bull 5: 539-545, 1980 .

34. Ross, D. A., S. D. Glick and R. C. Meibach. Sexually dimorphic brain and behavioral asymmetries in the neonatal rat. Proc Natl Acad Sci USA 78: 1958-1961, 1981.

35. Russell, P. A. "Infantile stimulation" in rodents: a consideration of possible mechanisms. Psychol Bull 75: 192-202, 1971.

36. Schapiro, S. and K. R. Vukovich. Early experience effects upon cortical dendrites: a proposed model for development. Science 167: 292-294, 1970.

37. Sherman, G. F., J. A. Garbanati, G. D. Rosen, M. Hofmann, D. A. Yutzey and V. H. Denenberg. Lateralization of spatial preference in the female rat. Life Sci 33: 189-194, 1983.

38. Sherman, G. F., J. A. Garbanati, G. D. Rosen, D. A. Yutzey and V. H. Denenberg. Brain and behavioral asymmetries for spatial preference in rats. Brain Res 192: 61-67, 1980.

39. Ungerstedt, U. Striatal dopamine release after amphetamine or nerve degeneration revealed by rotational behavior. Acta Physiol Scand 82: Suppl. 367, 49-68, 1971.

40. Walker, S. F. Lateralization of functions in the vertebrate brain: a review. Br J Psychol 71: 329-367, 1980.

41. Warren, J. M. Handedness and cerebral dominance in monkeys. In: Lateralization in the Nervous System, edited by S. Harnad et al. New York: Academic Press, 1977, pp. 151-172.

42. Weinberg, J. and S. Levine. Early handling influences on behavioral and physiological responses during active avoidance. Dev Psychobiol 10: 161-169, 1977.

43. Weinberg, J., E. A. Krahn and S. Levine. Differential effects of handling on exploration in male and female rats. Dev Psychobiol 11: 251-259, 1978 .

44. Winer, B. J. Statistical Principles in Experimental Design. New York: McGraw-Hill, 1971

45. Zimmerberg, B., S. D. Glick and T. P. Jerussi. Neurochemical correlate of a spatial preference in rats. Science 185: 623-625, 1974.

\section{NOTE ADDED IN PROOF}

Rosen et al. (Life Sci 34: 1143-1148, 1984) also recently reported that the DA content of the right nucleus accumbens is greater than the left. 